\title{
A DANÇA DO VENTRE EM FOCO: PRODUÇÕES CULTURAIS NA CIDADE DE LONDRINA - PARANÁ
}

\author{
Jaqueline Ramos Marra \\ Universidade Estadual de Londrina, Londrina, Paraná, Brasil. \\ Vitor Hugo Marani \\ Universidade Federal de Mato Grosso - Campus Araguaia, Pontal do Araguaia, Mato Grosso, Brasil \\ Silvia Pavesi Sborquia \\ Universidade Estadual de Londrina, Londrina, Paraná, Brasil.
}

\begin{abstract}
Resumo
A pesquisa objetivou identificar os grupos de dança do ventre e suas produções culturais na cidade de Londrina, Paraná, e investigar os sentidos e significados atribuídos à dança. A coleta de dados foi realizada a partir de análise documental e entrevistas semiestruturadas. $\mathrm{O}$ universo e a amostra foram constituídos pelos registros sobre as danças do ventre no Jornal Folha de Londrina de 1980 a 2010. A análise revelou a existência de dois grupos de dança do ventre na cidade, o que permitiu o diálogo com uma das professoras mais antigas com registros nos jornais e na Secretaria de Cultura de Londrina. A partir dos dados coletados, conclui-se que a dança do ventre na cidade se instaura como maneira de disseminar a cultura árabe a partir de diferentes elementos, a exemplo de aulas e produção de espetáculos e, ainda, produz-se por meio de processos culturais híbridos relacionados a outras manifestações dançantes.
\end{abstract}

Palavras-chave: Cultura. Dança. Dança do ventre.

\section{THE BELL DANCE IN FOCUS: CULTURAL PRODUCTIONS IN THE CITY OF LONDRINA - PARANÁ}

\begin{abstract}
The research aimed to identify the belly dance groups and their cultural productions in the city of Londrina - Paraná and investigate the meanings and meanings attributed to dance. The collection of data opted for documentary analysis and the semi-structured interview. The universe and the sample were constituted by records about the belly dances in the Folha de Londrina newspaper from 1980 to 2010. Based on the collected data, it is concluded that the belly dance in the city is established as a way of disseminating the Arab culture from different elements, such as classes and production of shows and, also, it is produced through processes cultural expressions related to other dance manifestations.
\end{abstract}

Key-words: Culture. Dance. Belly dance. 


\title{
LA DANZA DEL VENTRE EN FOCO: PRODUCCIONES CULTURALES EN LA CIUDAD DE LONDRINA - PARANÁ
}

\begin{abstract}
Resumen
La investigación objetivó identificar los grupos de danza del vientre y sus producciones culturales en la ciudad de Londrina- Paraná e investigar los sentidos y significados atribuidos a la danza. La recolección de datos optó por el análisis documental y la entrevista semiestructurada. El universo y la muestra fueron constituidos por los registros sobre las danzas del vientre en el Jornal Folha de Londrina de 1980 a 2010. A partir de los datos recolectados, se concluye que la danza del vientre en la ciudad se instaura como manera de diseminar la cultura árabe a partir de diferentes elementos, a ejemplo de clases y producción de espectáculos y, aún, se produce por medio de procesos culturales híbridos relacionados con otras manifestaciones bailables.
\end{abstract}

Palabras clave: Cultura. Danza. Danza del vientre.

\section{Introdução}

A dança é uma das mais antigas práticas corporais, pois a linguagem corporal é a primeira manifestação expressiva do ser humano (MOHAMED, 1995; WALTARI, 2002). Os povos manifestaram as práticas corporais dançantes em diversas ocasiões significativas da história e da cultura, tais como: festas, oferendas, rituais religiosos, em comemorações de nascimento, casamento, morte e, até mesmo, as comemorações ligadas à agricultura como a plantação e a colheita, ou seja, aos acontecimentos importantes da Antiguidade (GARAUDY, 1980; MOHAMED, 1995). A dança é considerada uma manifestação da expressividade humana produzida e reproduzida conforme o contexto, crenças, valores e características de cada grupo social (SBORQUIA e PÉREZ GALLARDO, 2006) e, por conseguinte, Sborquia e Neira (2008) a consideraram como um artefato cultural produzido pela gestualidade sistematizada.

A dança do ventre, objeto de estudo dessa investigação, é uma prática corporal carregada de sentidos e significados singulares manifestada pela cultura de etnias do Oriente. (BENCARDINI, 2002; HANNA, 1999). Conforme Oliveira (2011) e La Regina (1998), a terminologia mais apropriada e utilizada para a dança nos países árabes é Dança do Oriente. Os autores citados afirmam que foram os franceses que a batizaram de Dança do Ventre ou Dança do Estômago, embora outros povos tenham designado outras nomenclaturas, a exemplo dos americanos que a intitularam como Belly Dance e entre os egípcios como Raqs Sharqê.

Segundo Lyz (1999), a Dança do Ventre originou-se em vários países e sofreu influências dos costumes de cada região em que era praticada. Os cultos estavam ligados à deusa mãe em oferenda para a fertilidade. Tal manifestação dançante seguiu dois caminhos de desenvolvimento: o culto religioso e a dança dos palácios e das ruas. Reis (2008) afirma que a dança do ventre possui códigos simbólicos pertencentes aos templos, cuja crença à deusa mãe da Terra e dos seres humanos é a responsável pela fertilidade da terra. As sacerdotisas movimentavam seus ventres com vibrações e ondulações durante os rituais para homenagear a deusa e para garantir a prosperidade e fertilidade para as mulheres e para a terra. Reis e Zanella (2010) relatam que os significados da dança do ventre estavam relacionados ao sagrado e era praticado por sacerdotisas para homenagear o deus Rã (sol), exaltando energias da criação com enfoque de movimentos na região do útero.

Mohamed (1995) apresenta indicações de manifestações da dança do ventre em pinturas e esculturas do Egito faraônico. As análises iconográficas revelam as sacerdotisas prati- 
cando a dança nos templos e em eventos oficiais. Segundo o autor após a invasão árabe as essas obras artísticas mostram que a dança do ventre se configurava como espetáculos nos palácios para entreter a corte. Em seus relatos, menciona que em $1258 \mathrm{com}$ a radicalização do Islamismo e o fim do califado, a dança do ventre é ressignificada e passa a ser instrumento de sedução, pois por volta do século XVI, ainda no Egito, ela é manifestada em locais de prostituição, o que culminou na divulgação dessa manifestação a partir de elementos que fugiam à tradição e aos rituais sagrados nos quais se desenvolveu. Nesse sentido, ao longo da história, a dança do ventre se apropriou de outros elementos da cultura árabe como expressão artística e, tais significados, tiveram maior incidência na cultura ocidental e, consequentemente, seu sentido sagrado e sua tradição foram se perdendo. Corroborando com os fatos, Reis e Zanella (2010) afirmam que o imperador francês Napoleão Bonaparte se encantou com a dança do ventre após a invasão ao Egito no século XVIII. Tal fato refletiu no fortalecimento dessa prática corporal, além do mais, Abrão e Pedrão (2005) expõem os benefícios dessa prática relacionados, principalmente, à gestualidade feminina.

Mohamed (1995), Kussunoki e Aguiar (2009) argumentam que a dança do ventre é uma linguagem sensual e, por vezes, está relacionada à sexualidade e a sedução. Tais características a conduziram em apresentações em locais de shows e striptease em diferentes lugares do mundo. Por conseguinte, a dança do ventre ficou atrelada a conceitos estereotipados, distanciando-se da sua prática social original.

Segundo esses autores, na atualidade, em sua prática artística e cultural, o estilo egípcio da Dança do Ventre é o mais conhecido e nele se mesclam movimentos suaves e lentos com enérgicos e rápidos. A sua dança do bastão é largamente executada, sendo ensinada até mesmo em escolas, tanto a dança feminina quanto a masculina. Essa dança apresenta movimentos repetitivos, com a cabeça à direita e à esquerda, e para frente e para trás, de tal forma que os cabelos desenham formas no ar, com uma movimentação enérgica e veloz. No Líbano o ritmo é muito mais dinâmico e as dançarinas costumam apresentar com sapatos de salto alto. Na Turquia, por influência sufi, possui características mais espirituais, com predominância de movimentos de braços e de ombros. Reis (2008) identificou diferentes significados e funções sociais da Dança do Ventre retratados na história como aspectos lúdicos e de lazer, artístico, estético, religioso, trabalho e de sedução.

Não obstante, Namur (2007) apresenta ideias da escritora egípcia Nawal El-Saadawi, que traz à tona a categorização da mulher institucionalizada pelo sistema patriarcal: as mães puras, sagradas, castas, respeitáveis e esposas. E outra categoria na qual se agrupam as "mulheres manchadas", que seriam amantes, mulheres fogosas, sedutoras, mas desprezadas. Essa distinção tão estigmatizada é a crítica mais enfática da escritora em relação à imagem da mulher difundida e estereotipada na literatura árabe.

No Brasil, a manifestação da dança do ventre ocorreu de maneira relativamente recente, apresentando registros no início de 1970 (REIS, 2008). A partir de então, a dança do ventre se expandiu por diversos locais do Brasil, os principais locais dessa manifestação são as escolas de dança, restaurantes árabes, festas e casamentos árabes. Atualmente tem ganhado espaço em âmbito nacional, entretanto Mohamed (1995) afirma que as produções artísticas dessa manifestação têm maior representação no estado de São Paulo em razão de ter o maior número desses imigrantes no país de acordo com Rondinelli (2002).

No Paraná, estado em que a referente pesquisa foi desenvolvida, Carloto (2007) explica que há concentração da comunidade árabe-muçulmana, principalmente, nas cidades de Foz do Iguaçu e Londrina. Especificamente, em Londrina, a Mesquita da cidade, denominada de Rei Faiçal e Sunita, foi a segunda mesquita a ser construída no Brasil, em 1973. Esse fato corroborou a importância de se investigar a presença da dança na cultura local, percebendo os significados construídos em torno dessa manifestação estética. Tal interesse foi desenvolvido, num primeiro momento, a partir das pesquisas realizadas pelo Grupo de Pesquisa Gestualida- 
de, Ludicidade e Cultura - GESLUC, as quais se preocupavam em mapear as danças existentes na cidade de Londrina a partir dos registros no Jornal Folha de Londrina, entre 1980 e 2010. A inferência aos dados revelou uma diversidade cultural relacionada a diversas expressões dançantes, a exemplo do Balé Clássico, da Dança Flamenca, da Dança de Rua, da Dança de Salão, da Dança Afro-Brasileira, da Dança Japonesa e da Dança Árabe, foco nesse estudo.

Por isso, o presente artigo buscou identificar os grupos de dança do ventre e suas produções culturais na cidade de Londrina, Paraná, bem como investigar os sentidos e significados atribuídos à dança na referida localidade. $\mathrm{O}$ interesse por esta investigação deu-se em razão da necessidade de conhecer as diferenças culturais manifestadas pela dança. A razão de pesquisarmos sobre a dança decorre do fato de termos percebido que esse conhecimento dificilmente é tratado no âmbito acadêmico e poucos são os registros sobre os grupos minoritários. Resulta daí a necessidade de estudos que investiguem a dança como um fenômeno cultural e, por conseguinte, como manifestação da gestualidade humana carregada de códigos simbólicos presente nos mais diversos grupos sociais. Consideramos que todo o conhecimento é local e total, constitui-se em redor de temas que em dado momento são adotados por grupos sociais concretos como projetos de vida locais (SANTOS, 2003).

Ainda, é importante ressaltar a ideia de que, a dança, embora compreendida como manifestação corporal presente em diferentes temporalidades, evidentemente recebeu olhares focalizados em territorialidades ocidentais, especificamente, em países em que a industrialização apresentou maiores avanços na modernidade. Por isso, aponta-se a interlocução com o tema e seus elementos constitutivos a partir de outras técnicas corporais, entendendo que o fomento de reflexões advindas de diferentes contextos pode contribuir para o aprimoramento epistemológico da referida manifestação, como sugere Lara (2013). Parte-se do pressuposto de que a dança, inserida na cultura corporal de movimento, envolve o conjunto de saberes de todas as manifestações humanas nas quais o movimento transporta e conduz significados culturais, produzida e reproduzida conforme o contexto, crenças, valores e características de cada grupo social, portanto, um artefato cultural produzido pela gestualidade sistematizada (NEIRA, NUNES, 2006).

\section{Metodologia}

O presente estudo caracterizou-se como uma pesquisa qualitativa de caráter descritivo e documental, buscando utilizar métodos de investigação e critérios epistemológicos qualitativos com vistas à obtenção de um conhecimento interpretativo, descritivo e compreensivo, com base nas contribuições de Santos (2003), Minayo (1996) e Triviños (1997). O presente artigo estrutura-se como resultado de projeto de investigação institucional que se preocupou com a compreensão dos significados culturais da dança na cidade de Londrina, aprovado pelo Comitê de Ética por meio do Parecer n. ${ }^{\circ}$ 01888712.5.0000.5231. O procedimento de coleta de dados foi realizado por meio de fotografias e digitalização das imagens do acervo de 10.800 edições do Jornal Folha de Londrina disponível no Centro de Documentação e Pesquisa Histórica da Universidade Estadual de Londrina, tendo como amostra os registros sobre a dança do ventre.

A análise dos jornais identificou a existência de dois grupos de Dança do Ventre na cidade nas décadas investigadas. Além disso, averiguou-se junto à Secretaria de Cultura da Cidade os registros desses grupos de Dança do Ventre, resultando em apenas um grupo encontrado, o que permitiu o acesso a informações relacionadas à sua coordenação. Diante disso, foi selecionado para a entrevista o grupo com registros nos jornais e na Secretaria da Cultura, culminando em segundo momento, na realização de entrevista semiestruturada com o líder do grupo de Dança do Ventre. A entrevista seguiu os procedimentos da análise de conteúdo temática. 
A análise dos dados seguiu os princípios da análise de conteúdo temático (BARDIN, 1977). Além disso, buscou-se uma interpretação histórica dos dados obtidos (RICHARDSON, 1999). O tratamento dos dados coletados seguiu um processo de interpretação, que implica um constante movimento entre as partes e o todo, buscando contextualizar o significado da expressão humana e de não divorciá-lo desse contexto (SÁNCHES GAMBOA, 2000). Daí o estudo apresentar subsídios para entender a etnia árabe presente no Brasil, embora focalizada num contexto localizado, com o intuito de perceber como o campo gestual se afirma e, ao mesmo tempo, se desloca a partir de processos de hibridização cultural em meio à sociedade globalizada.

\section{Dimensões Culturais Da Dança Do Ventre Na Cidade De Londrina - Paraná}

A coleta de dados junto ao Jornal Folha de Londrina, a partir do recorte temporal de 1980 a 2010, permitiu o acesso a trinta e duas reportagens na Folha 2 do jornal, que continham registros sobre a Dança do ventre. Verificou-se a utilização de imagens relacionadas à dança na maioria dos exemplares, que tomavam conta de, pelo menos, meia página do jornal. Em sua maioria, a análise das imagens teve característica de divulgação da realização de festivais e espetáculos que aconteciam em teatros, bares e restaurantes na cidade juntamente a suas professoras e proprietárias das escolas de dança.

No início da década de 1980, em especial no ano de 1984, foi encontrado um registro com relatos sobre a Dança do Ventre na cidade, realizado no Canada Country Clube e recebeu o nome "Mil e uma noites". Já na década de 1990, foram encontradas seis reportagens sobre Dança do Ventre. Dessas reportagens, cinco divulgavam as produções da Escola de Dança do Ventre Rhamza Alli. A partir de diferentes buscas, foi possível compreender que tal escola foi responsável por promover cursos e espetáculos de dança, os quais foram apresentados em teatros e escolas. Em duas reportagens foram encontradas entrevistas com a professora de um dos grupos, apresentando os aspetos históricos e culturais da Dança do Ventre.

Em entrevista com Rhamza Alli, a professora da escola homônima relata que a Dança do Ventre é uma arte incorporada ao inconsciente coletivo como um artifício de sedução. Nos anos de 1930 e 1940 o cinema trouxe a "dança da sedução" para a América. Na sua origem, a dança era um atributo das princesas nos haréns ou das sacerdotisas nos templos. Eram movimentos desenvolvidos pelas mulheres para as mulheres (MUSSILI, 30 set. 1998, Folha 2).

Os registros a partir do início do século XXI mostraram uma maior valorização das manifestações da Dança do Ventre na cidade. Verificou-se a existência de duas escolas na cidade: a Escola de dança do ventre Rhamza Alli e a Escola Origens Renata Lobo, ambas existentes na cidade atualmente.

Em outra entrevista com Musilli (2002), Rhamza Alli apresentou os aspectos históricos e culturais sobre os significados da dança do ventre. Dentre eles, destacaram-se os aspectos de gênero presentes nesta manifestação cultural.

Uma menina nascida em uma comunidade árabe é apresentada ao que é conhecido no ocidente como "dança do ventre" quando de sua menarca. Nesta ocasião, ela é retirada de seu mundo infantil e iniciada em diversos movimentos e exercícios que têm como objetivo o fortalecimento de seus órgãos reprodutores, músculos abdominais e internos da coxa, a fim de desenvolver um corpo forte para gestações tranquilas, partos naturais e menos dolorosos. Esta é a original função da dança. Antes de se tornar "mulher" os órgãos reprodutores ainda não estão em funcionamento e muitas mudanças ainda acontecerão. Os exercícios da dança do ventre atuam principalmente nestes órgãos trabalhando contrações de diversos pontos que podem interferir no desenvolvimento e na maturidade sexuais da menina. Além disso, os movimentos ondulatórios e sensuais influenciam diretamente o psicológico da criança. A sexualidade e sensualidade têm seu tempo de acontecer e fluem naturalmente com a pu- 
berdade, forçá-las a acontecer, mesmo que inconscientemente, pode trazer sérias consequências (MUSSILI, 9 mar. 2002, Folha 2).

A reportagem traz relatos da professora que argumenta que o fato da dança ter se aberto ao ocidente não nos dá o direito de atropelar uma cultura milenar e expormos nossas meninas a prática de exercícios destinados às mulheres, como pode ser observado no excerto a seguir:

O fato de a televisão mostrar crianças executando uma suposta dança do ventre não significa que isso seja bom ou benéfico. As antigas tradições têm sua razão de ser, os movimentos da dança do ventre são muito eficientes e benéficos, mas, mal direcionado podem causar sérios danos ao funcionamento dos órgãos abdominais (reprodutores, digestivos, respiratórios), além de outros causados por qualquer exercício errado: coluna, ligamentos, articulações, etc. Tudo na vida tem seu tempo, [...] a dança do ventre também tem sua hora: é a partir da puberdade, criança é criança, a infância dura tão pouco para que encurtá-la? (MUSILLI, 9 mar. 2002, Folha 2).

Reis (2008) afirma que não existem estatísticas precisas, mas o crescimento dessa dança no Brasil pode ser indiretamente inferido a partir da observação do grande número de escolas de dança em diversas cidades brasileiras oferecendo aulas nessa modalidade. A análise dos registros possibilitou perceber que esse fenômeno também ocorreu na cidade de Londrina, no interior do Paraná. Cunha (2010) afirma que a dança do ventre atualmente é ensinada por diversas professoras que coordenam desde pequenos grupos informais até grandes companhias de dança, e sobrevivem de seu ensino e de apresentações performáticas.

Com base no exposto, optamos por entrevistar a professora mais antiga da cidade, que possui registros de projetos na Secretaria da Cultura da cidade. Rhamza Alli veio para Londrina em 1996. O interesse pela Dança do Ventre adveio de sua descendência de origem árabe da Síria. Embora descendente da cultura árabe, não aprendeu a dança com sua mãe. Iniciou seus estudos em balé clássico e, depois, Dança do Ventre. Os sentidos e significados da dança mostraram a necessidade de resgatar a sua cultura de origem e, posteriormente, transmiti-la como forma de trabalho. $\mathrm{Na}$ entrevista, ela afirma que a dança do ventre revelou o sentido da vida para ela:

[...] têm muitos movimentos que vão se juntando um ao outro, os dois símbolos principais são: o oito que é o infinito da vida e a bolinha que é o início da vida. Com essas duas formas a gente trabalha muito tanto nas mãos como no quadril, com basicamente essas duas formas de várias maneiras formam vários passos que são os movimentos que se dividem em três tipos de movimentos, os ondulatórios, os de impactos e as tremidas.

Segundo Dantas (1999), na dança, o corpo transfigura-se em formas. Na Dança do Ventre as formas se configuram na figura do número oito, nos círculos e ondas. Nesse processo o sujeito transcende sua existência. "O eu não é uma instância incorpórea, abstrata e imaterial que habita ou possui um corpo. O sujeito não tem um corpo. O sujeito é corpo" (REIS, 2007, p. 41).

As danças produzidas pelo grupo buscam manifestar a tradição de origem Oriental. Consideramos danças tradicionais aquelas cujos elementos coreográficos centrais se definem por sua origem mítica, religiosa, ritualística, mágica, com uso determinado por regras prefixadas e sua transmissão de geração em geração, restringe-se a uma dada coletividade (CASCUDO, 1971). Yunis (2013) mostra que há, ainda, as danças cênicas e as representações 
das tradições, sendo necessário observar o hibridismo que mescla os aspectos da tradição com os princípios cênicos.

Dentre as manifestações apresentadas pelo grupo houve o relato de diferentes expressões artísticas, a saber:

a) Raks El Sharqi: estilo clássico da dança do ventre composto por movimentos do ballet clássico; b) Dança dos Sete Véus: uma dança sagrada onde cada véu corresponde a um grau de iniciação; c) Dança do Candelabro (Raks El Shemadan): simboliza o equilíbrio entre o céu e a terra; d) Dança do Jarro: é originária dos rituais de nascimentos e representa as mulheres que saem de suas tendas e vão buscar água no Rio Nilo; e) Dança das Velas: simbolizam a espiritualidade e a festividade, como o casamento e a maternidade; f) Solo de Derbake: a sacerdotisa acompanhava as batidas fortes da percussão com precisão, exaltando as forças da terra; g) Dança da Bengala ou Espada (Raks Al Assaya): dança na qual mulheres parodiam a luta dos homens com os bastões; h) Dança do Pandeiro (Snujs/Sagats): representa a tradição do Egito Antigo, em que bailarinas costumavam estalar os dedos para acompanhar o ritmo da música; i) Dança do Punhal: de origem turca esta dança reverencia a deusa Selkis, a Rainha dos Escorpiões, na qual há simbolismo da morte, do sexo e da transformação; j) Dança da Serpente: por ser um animal considerado sagrado e símbolo da sabedoria, antigamente as sacerdotisas dançavam com uma serpente de metal (muitas vezes de ouro).

Sobre a transmissão cultural da dança, os relatos mostraram que quando a dança do ventre chegou ao ocidente foi coreografada para ser inserida em espetáculos, cassinos, casa de show, hotéis, entre outros espaços performáticos. Portanto, sua forma de transmissão e recepção acabou sendo (re)significada ao longo dos anos, como é possível compreender a partir do trecho retirado da entrevista e disponível abaixo:

\begin{abstract}
A transição para o Ocidente acarretou em ressignificações e hibridização da Dança do Ventre, que recebeu influências e incorporou movimentos de muitas outras danças e culturas. Atualmente, é possível observar várias fusões com as danças típicas de outras etnias, como a dança cigana, flamenca, indígena, indiana etc. Parece evidente que os contatos interétnicos propiciaram a criação de novas formas de dançar que diferem da dança tradicional e clássica. Fala-se muito em dança tribal, Belly Jazz (Dança do Ventre com movimentos do Jazz), Zambra (Dança do Ventre com movimentos da dança flamenca), Belly Tango (fusão de tango com Dança do Ventre), etc. Segundo as professoras, alguns passos usados no balé também foram incorporados à Dança do Ventre, como o Arabesque, Cambré e Chassé.
\end{abstract}

O recorte acima elucida aspectos que fazem referência a diversas manifestações artísticas que, na atualidade, passaram por diversas transformações com o intuito de atender demandas estéticas de diferentes grupos sociais. Com isso, nota-se que, a partir da entrevista, a dança do ventre em Londrina-Paraná, assim como outros estilos, também se construiu a partir de processos de hibridização, dada sua (re)interpretação junto a outras manifestações dançantes, utilizando de novos movimentos, novos instrumentos musicais, novas vestimentas, entre outros elementos que auxiliaram nessa construção estética reformulada. Entretanto, é importante afirmar que, embora tais mudanças possam ser evidenciadas, isso não faz com que pensemos que a tradição tenha sido encerrada, pelo contrário, (re)afirma processos de resistência e conformismo assumidos por diferentes grupos em seu modo de organização frente à sociedade.

Ainda, os dados mostraram que poucas apresentações são realizadas na cidade, geralmente em teatros, no centro cultural. Tais espetáculos acontecem uma vez ao ano. Por outro lado, também ocorrem apresentações em festas particulares ou casamentos, aniversários e 
muitas festas de empresas e escolas. Reis e Zanella (2010) dizem que função de entretenimento nas festas Árabes da Dança do Ventre foi associada ao período em que era realizada nos haréns (Turquia, século XV). Deste modo, verifica-se que nas festas e casamentos que mantém a tradição das Danças Árabes vincula o papel simbólico feminino a estas figuras representativas dos haréns e não ao lugar em que a sexualidade feminina é resgatada como manifestação da divindade pelo seu poder de gerar a vida, associada ao sagrado.

\section{Considerações Finais}

O interesse central do artigo esteve respaldado pela identificação dos grupos de Dança do Ventre e suas produções culturais na cidade de Londrina, Paraná, bem como pela investigação dos sentidos e dos significados atribuídos à dança na referida localidade. A partir da investigação foi possível perceber que Londrina possui significativa população de imigrantes árabes que influenciam na cultura local e, por isso, sua presença também é manifestada por meio da Dança do Ventre com a tradição de escolas de dança, festivais e festas com apresentações dos grupos locais.

A Dança do Ventre se caracteriza como tradição da cultura árabe na cidade desde 1997, momento em que houve a inauguração da primeira escola dessa dança em Londrina, o que permitiu investigar tal manifestação a partir dos diferentes espetáculos realizados pela escola, o que oportunizou o (re)conhecimento dessa cultura. Para além, identificou-se a Dança do Ventre como constitutiva dos ritos de iniciação à vida adulta, pois após a menarca a menina aprende os movimentos da dança a fim de fortalecer os órgãos reprodutores e preparar-se para a gestação e o parto. Cada gesto traz o seu sentido e significado desde a bolinha que é o início da vida até o oito que é o infinito. As (re)formulações dessa dança revelam a densa tradição de uma cultura milenar carregada de códigos simbólicos históricos e sociais que se mantém nestas escolas e é, ao mesmo tempo, ressignificada nos espetáculos, o que aponta para as escolas de dança árabe como elementos fundamentais para a construção da diversidade cultural na cidade.

Com base no exposto, podemos concluir que a dança árabe manifestada na cidade se constitui como um posicionamento de resistência em defesa da manutenção das tradições étnico-raciais. Percebe-se um trabalho que, ao mesmo tempo, nega a padronização e também luta contra todas as formas de desigualdade e discriminação presentes na sociedade e, principalmente, na mídia que padroniza e promove a desigualdade. A igualdade pautada na justiça e na democracia assume e reconhece os direitos básicos de todos. Porém, cada pessoa, cada grupo social possui uma singularidade própria e é por isso que tem que ter as suas diferenças reconhecidas em condições de alteridade.

Por fim, é importante considerar que a sociedade atual envolta pela globalização não permite a sustentação da ideia de sociedades monoculturais, marcadas pelos princípios da homogenização das linguagens, dos costumes, de comportamentos e atitudes, dentre outros significados. Cada vez mais, emerge a necessidade de pensar a diversidade e pluralidade cultural, que ao mesmo tempo em que se (re)significa, também, mantém a tradição de diversas manifestações, como é o caso de diferentes expressões dançantes. Daí a necessidade de investigações que estejam pautadas no entendimento de valorização e (re)conhecimento dessas produções culturais em diferentes localidades. 


\section{Referências}

ABRÃO, A. C. P, PEDRÃO, L. J. A contribuição da dança do ventre para a educação corporal, saúde física e mental de mulheres que frequentam uma academia de ginástica e dança. In: Rev. Latino-am Enfermagem, v. 13, n. 2, p. 243-248, 2005.

BARDIN, L. Análise de Conteúdo. Lisboa: Edições 70, 1977.

BENCARDINI, P. Dança do ventre: ciência e arte. São Paulo: Texto novo, 2002.

CAMARGO, F. M. T; SBORQUIA, S. P. Mapeamento dos grupos de dança em Londrina-PR. In: $22^{\circ}$ Encontro Anual de Iniciação Científica e $3^{\circ}$ Encontro Anual de Iniciação Tecnológica e Inovação, 2013, Londrina. Anais [...], 2013.

CASCUDO, C. Tradição, ciência do povo. São Paulo: Perspectiva, 1971.

CARLOTO, D. R. O Espaço de representação da comunidade árabe-muçulmana de Foz do Iguaçu-PR e Londrina-PR: Diáspora e Multiterritorialidade. 2007. 120f. Dissertação (Mestrado em Geografia) - Universidade Federal do Paraná. Curitiba, 2007.

CUNHA, A. Reflexões sobre o ensino de Dança do Ventre. 2010. 99f. Trabalho de conclusão de curso (graduação) Universidade do Estado de Santa Catarina - UDESC. Florianópolis, 2010 .

DANTAS, M. Dança: o enigma do movimento. Porto Alegre: Editora UFRGS, 1999.

GARAUDY, R. Dançar a vida. 6. ed. Rio de Janeiro: Nova Fronteira, 1980.

GEERTZ, C. A interpretação das culturas. Rio de Janeiro: Guanabara Koogan, 1989.

GEERTZ, C. O Saber local: Novos ensaios em antropologia interpretativa. Petrópolis, RJ: Vozes, 1997.

HALL, S. Da diáspora: identidades e mediações culturais. Belo Horizonte: UFMG, 2003.

HANNA, J. L. Dança, sexo e gênero: signos de identidade, dominação, desafio e desejo. Rio de Janeiro: Rocco, 1999.

KUSSUNOKI, S. A. Q.; AGUIAR, C. M. Aspectos históricos da dança do ventre e sua prática no Brasil. Revista Motriz, Rio Claro, v.15 n.3 p.708-712, jul./set. 2009.

LARA, L. M. Dimensão epistemológica da dança: leituras, prospecções incompletudes. In: Larissa Lara. (org.). Dança: dilemas e desafios na contemporaneidade. 1. ed. Maringá: Eduem, 2013.

LA REGINA, G. Dança do ventre: uma arte milenar. 1. ed. São Paulo: Moderna, 1998.

LYZ, S. Dança do Ventre: descobrindo sua deusa interior. São Paulo: Berkana Editora, 1999. 
MINAYO, M. C. S.S. (org). Pesquisa Social: teoria, método e criatividade. Petrópolis, RJ: Vozes, 1996.

MOHAMED, S. La danza mágica del vientre. 1. ed. Madrid: Mandala, 1995.

MUSILLI. Mil é uma dança. Canada Country Clube. Londrina. 30 set. 1998, Folha 2.

MUSILLI. Dança do ventre. Escola de Dança do Ventre Rhamza Alli. Londrina. 9 mar. 2002, Folha 2.

NAMUR, M. Sincretismo cultural sob a óptica de gênero e imagens de mulher na literatura árabe-brasileira. 2007. Dissertação (Mestrado em Ciências Sociais Aplicadas Interdisciplinar) - Universidade Estadual de Ponta Grossa, Ponta Grossa, 2007.

NEIRA, M. G.; NUNES, M. L. F. Pedagogia da cultura corporal: Crítica e alternativas. São Paulo: Phorte, 2006.

OLIVEIRA, E. S. DE. Dança do Ventre: técnica, expressão, significados. Uma etnografia nas Escolas de dança em Pelotas/RS. 2011. 130 f. Dissertação (Mestrado em Ciências Sociais). Universidade Federal De Pelotas, Pelotas, 2011.

REIS, A. C. A atividade estética da dança do ventre. Dissertação (Mestrado em Psicologia) Universidade Federal de Santa Catarina, Florianópolis, SC, 2007.

REIS, A. O feminino na dança do ventre: Uma análise histórica sob uma perspectiva de gênero. Revista Eletrônica Interdisciplinar, Matinhos, v. 1, n. 1, p. 52-67, 2008.

REIS, A.C, ZANELLA, A.V. A constituição do sujeito na atividade estética da dança do ventre. Revista Psicologia \& Sociedade, v. 22, n. 1, p. 149-156, 2010.

RICHARDSON, R. J. Pesquisa Social: métodos e técnicas. São Paulo: Atlas, 1999.

RONDINELLI, P. Entre a deusa e a bailarina: a polifonia cultural da dança do ventre. 2002 . 94 f. Dissertação (Mestrado) Instituto de Biociências, Universidade Estadual Paulista, Rio Claro, 2002.

SÁNCHES GAMBOA, S. (org.) Pesquisa Educacional: quantidade-qualidade. $3^{\circ}$ ed. São Paulo: Cortez, 2000.

SANTOS, B. S. Um discurso sobre as ciências. São Paulo: Cortez, 2003.

SBORQUiA, S. P.; PÉREZ GALlARDO, J. S. A Dança no Contexto da Educação Física. Ijuí: Ed. Unijuí, 2006.

SBORQUIA, S. P.; NEIRA, G. N. As Danças Folclóricas e Populares no Currículo da Educação Física: possibilidades e desafios. Revista Motrivivência. Ano XX, n. 31, p. 79-98. Dez, 2008.

TRIVIÑOS, A. M. Introdução à pesquisa em Ciências Sociais: a pesquisa qualitativa em educação. São Paulo: Atlas, 1997. 
WALTARI, M. O egípcio. 1 ed. Belo Horizonte: Itatiaia, 2002.

YUNIS, L. E. Êxtase, poesia e dança em Rumi e Hafiz 2013. 128 f. Dissertação (Mestrado em Estudos Judaicos e Árabes) Universidade de São Paulo. São Paulo, 2013.

Recebido em: 28/08/2018

Revisado em: 29/10/2018

Aprovado em: 27/02/2019

Endereço para correspondência:

vitorhmarani@gmail.com

Vitor Hugo Marani

Universidade Federal de Mato Grosso

Campus Universitário do Araguaia, Brasil.

Avenida Universitária $\mathrm{n}^{\circ} 3.500$.

Pontal do Araguaia - Mato Grosso

78698 - 000 Mato Grosso -MT, Brasil. 